\title{
Avaliação das propriedades mecânicas do músculo gastrocnêmio de ratas imobilizado e submetido à corrente russa
}

\author{
Mechanical property analysis of the gastrocnemius muscle of rats immobilized and \\ submitted to the Russian current
}

\author{
Douglas Reis Abdalla ${ }^{1}$, Dernival Bertoncello ${ }^{2}$, Leonardo Céar Carvalho
}

Estudo desenvolvido nos

Laboratórios de Bioengenharia

e Pesquisa em Materiais

Odontológicos da Uniube-

Universidade de Uberaba,

Uberaba, MG, Brasil

1 Fisioterapeuta; mestrando em Patologia Geral na UFTM Universidade Federal do Triângulo Mineiro, Uberaba, MG

2 Fisioterapeuta; Prof. Dr. Adjunto do Curso de Fisioterapia da UFTM

3 Fisioterapeuta; Prof. Dr. do Curso de Fisioterapia e do Laboratório de Bioengenharia da Uniube

\section{ENDEREÇO PARA} CORRESPONDÊNCIA

Leonardo César Carvalho R. Vital de Negreiros 607 Fabrício

38065-300 Uberaba MG e-mail: leoncesa@terra.com.br

O estudo recebeu financiamento do Pape da Uniube

\section{Apresentação out. 2008 \\ AceITo PARA PUBLICAÇÃo mar. 2009}

Resumo: A eletroestimulação neuromuscular por corrente russa, recurso utilizado na reabilitação, pode aumentar o trofismo e restabelecer a força muscular, sobretudo dos músculos que apresentam deficit pós-imobilização, como é o caso de lesões durante a prática esportiva. Objetivou-se avaliar as propriedades mecânicas do músculo gastrocnêmio de ratas imobilizadas por 14 dias e posteriormente submetidas à eletroestimulação por corrente russa durante 10 dias. Utilizaram-se 32 ratas Wistar divididas em quatro grupos: controle (G1), imobilizado (G2); imobilizado e liberado por 10 dias (G3) e imobilizado e submetido à corrente russa por 10 dias (G4). A avaliação das propriedades mecânicas - carga, alongamento, rigidez e resiliência - foi feita por ensaio de tração longitudinal. Quanto à carga no limite máximo, o G4 apresentou valores mais elevados quando comparado ao grupo apenas imobilizado (G2, $p<0,001)$, embora sem atingir o valor do G1. Na análise da propriedade de alongamento no limite máximo, G3 e G4 alcançaram valores significativamente maiores que o G2 $(p<0,001)$. No que se refere à rigidez, apenas $\mathrm{G} 2$ alcançou valores maiores $(p<0,05)$ que o G1. Quanto à resiliência, G4 apresentou valores inferiores ao grupo controle $(p<0,05)$, mas ainda superiores aos do G2 $(p<0,001)$. Portanto conclui-se que a corrente russa, quando aplicada por 10 dias após 14 dias de imobilização, é benéfica, embora não seja capaz de restabelecer todas as propriedades mecânicas do músculo em nível controle.

Descritores: Estimulação elétrica; Imobilização; Músculo esquelético

ABSTRACT:Neuromuscular electric stimulation by Russian current, used in rehabilitation, is able to increase muscle trophism and strength, especially in muscles with postimmobilization deficit, as is the case of injuries during sports practice. The purpose here was to assess the gastrocnemius muscle mechanical properties of rats immobilized for 14 days and subjected to electric stimulation by Russian current for 10 days. Thirty two Wistar female rats were divided into four groups: control (G1), immobilized (G2), immobilized and freed (G3), and immobilized and afterwards submitted to Russian current (G4). Mechanical properties - maximum load and stretch, stiffness, and resilience - were assessed by longitudinal traction. As to maximum load, G4 showed higher values when compared to the onlyimmobilized group (G2, $p<0.001)$, though not attaining $\mathrm{G} 1$ values. In the analysis of maximum elongation results, G3 and G4 presented significantly higher values than G2 $(p<0.001)$. Concerning stiffness, only $\mathrm{G} 2$ reached higher values $(p<0.05)$ than G1. As to resilience, G4 presented significantly lower values than G1 $(p<0.05)$, but still higher than G2's $(p<0.001)$. Hence the study showed that Russian current, applied for 10 days after a 14-day immobilization, is beneficial, though not able to restore all the muscle mechanical properties at control level.

KEy worDs: Electric stimulation; Immobilization; Muscle, skeletal 


\section{INTRODUÇÃO}

Estudos da mecânica corporal e seus segmentos são indispensáveis para a intervenção terapêutica. A combinação entre o conhecimento biomecânico e histomorfofuncional dos tecidos biológicos, principalmente do sistema musculoesquelético, é importante para o esclarecimento de lesões e alterações nas capacidades adaptativas ${ }^{1,2}$.

As lesões musculares dos esportistas continuam sendo um tema de constante atualização para os especialistas que têm a responsabilidade de manter em excelentes condições a estrutura osteomioarticular dos atletas, possibilitando assim melhor rendimento físico, técnico e tático ${ }^{3}$.

A imobilização, método de tratamento ainda muito usado após lesões, leva a várias complicações após prolongado período ${ }^{4,5}$. A imobilização de um segmento corpóreo é o repouso local, contínuo e rígido, utilizada em casos de fraturas, luxações, traumas musculares, manipulações cirúrgicas e outras enfermidades $^{6}$. As alterações induzidas pela imobilização não se limitam apenas ao músculo, pois comumente são observados transtornos de inervação e circulação, perda de massa óssea, alterações ligamentares, edema e rigidez articular ${ }^{6}$.

No músculo imobilizado, a partir de seis horas da imobilização, ocorre perda de proteínas, porém sem alteração da quantidade de mioglobina ${ }^{7}$. A partir do sétimo dia de imobilização, começam a reduzir-se o tecido conectivo e as fibras musculares por área de secção do músculo, promovendo alterações como atrofia e redução da atividade contrátil ${ }^{8-10}$. Como efeito da imobilização, pode-se evidenciar atrofia muscular e perda exponencial de massa do músculo esquelético em relação ao tempo, em função da diminuição do número de miofibrilas em paralelo e do número de fibras por músculo ${ }^{11,12}$.

A imobilização temporária, por curto período, permite a formação do tecido de granulação, o que propicia ao músculo esquelético força tênsil apropriada e resistência às forças criadas pela contração muscular ${ }^{13}$. É benéfica na fase precoce da regeneração muscular, de- vendo permanecer apenas durante os primeiros dias após a lesão ${ }^{14}$.

O trabalho da fisioterapia desportiva torna-se bastante diferente dos outros. É preciso rapidez e funcionalidade efetivas, pois o atleta precisará executar todas as funções dos músculos, ossos e articulações, no máximo de potência e amplitude, para o perfeito desempenho dos movimentos ${ }^{15}$. Assim, necessitam-se recursos que tornem a reabilitação mais acelerada.

A estimulação elétrica neuromuscular (EENM) para ativação do músculo esquelético é uma técnica terapêutica que tem sido utilizada na medicina física por mais de meio século. A partir dos anos 1960, o uso da EENM passou a focalizar principalmente o controle da atrofia muscular por desnervação ${ }^{16}$.

A corrente russa é uma corrente sinusoidal alternada (bifásica) de 2.500 $\mathrm{Hz}$. As correntes elétricas de média freqüência ocupam medidas entre 1.000 $\mathrm{Hz}$ e $100.000 \mathrm{~Hz}$, sendo múltiplas as vantagens de sua utilização. A principal é a melhor tolerabilidade à corrente pelo indivíduo submetido à EENM. Essa corrente é capaz de produzir níveis mais profundos de contração muscular, além de aumentar a força, sendo mais indicada para tratar músculos com inervação preservada $^{16}$.

A base teórica para o uso da corrente russa está na capacidade em que a estimulação elétrica máxima pode fazer com que quase todas as unidades motoras no músculo se contraiam de forma sincronizada, algo que não pode ser conseguido na contração voluntária. Isso permite a ocorrência de contrações musculares mais fortes com a estimulação elétrica e, portanto maior ganho de força acompanhado de hipertrofia muscular ${ }^{17}$. A capacidade que a Corrente Russa tem de produzir maior força muscular, acompanhada de menor fadiga, resultado de um programa que apresenta períodos de $10 \mathrm{~ms}$ de excitação, seguido por $50 \mathrm{~ms}$ de repouso, propriedade que respeita os períodos refratários da célula ${ }^{17}$. Com finalidade de fortalecimento recomenda-se tipicamente a utilizar freqüências de 35 a $85 \mathrm{~Hz}^{18}$.

Tendo em vista o reduzido acervo de trabalhos que abordem tal assunto, e a importância que este pode ter para estudos sobre imobilização, a presente pesquisa teve por finalidade verificar o efeito da aplicação de corrente russa sobre as propriedades mecânicas do músculo gastrocnêmio de ratas imobilizadas por 14 dias na posição de encurtamento e, posteriormente, eletroestimulado por corrente russa durante 10 dias. O músculo gastrocnêmio foi utilizado por apresentar melhor facilidade de localização e função e, ainda, porque após dissecação é possível manter origem e inserção óssea, possibilitando ensaio de tração mecânica.

\section{METODOLOGIA}

Foram utilizadas 32 ratas Wistar fêmeas com média de massa corpórea inicial $220,75 \pm 20,11 \mathrm{~g}$. Todos os procedimentos aos quais os animais foram submetidos tiveram a aprovação do Comitê de Ética no Uso de Animais da Universidade de São Paulo (campus de Ribeirão Preto), que seguem o International Guiding Principles for Biomedical Research Involving Animals.

Os animais doram divididos em quatro grupos, assim caracterizados:

1 G1 composto por 8 animais que permaneceram em observação 14 dias em gaiola padrão, isentos de qualquer intervenção;

2 G2 composto por 8 animais que tiveram o membro posterior direito imobilizado em flexão plantar por 14 dias.

3 G3 composto por 8 animais que tiveram o membro posterior direito imobilizado por 14 dias e liberado do aparelho gessado por 10 dias.

4 G4 composto por 8 animais que tiveram o membro posterior direito imobilizado por 14 dias e em seguida submetido à eletroestimulação por corrente russa durante 10 dias consecutivos.

Para a imobilização do membro posterior direito dos animais, foi feito um aparelho gessado que incluía pelve, quadril e joelho em total extensão e a articulação do tornozelo em flexão plantar. Os animais foram previamente anestesiados com cloridrato de ketamina (50 mg/kg) 
e xilazina $(15 \mathrm{mg} / \mathrm{kg})$ : a anestesia foi utilizada para preservação da integridade dos animais no que diz respeito ao estresse do procedimento e para facilitar o emprego da técnica, para que não houvesse movimentos compensatórios pelos animais. O período em que ficaram anestesiados variou de 10 a $20 \mathrm{mi}-$ nutos. Após a efetivação da anestesia, as ratas tiveram o membro posterior direito e cintura pélvica envolvidos por uma malha tubular e ataduras de algodão, a fim de evitar ulcerações, e por uma atadura gessada de secagem rápida com 2,5 cm de largura, aplicada de maneira convencional. O gesso foi substituído quando necessário, respeitando o mesmo procedimento. Os animais permaneceram imobilizados por duas semanas (14 dias consecutivos) mantidos a dois por gaiola com livre acesso a água e ração. A imobilização gessada não impediu a alimentação nem a locomoção dos animais dentro da gaiola.

Para a intervenção terapêutica por meio de estimulação elétrica neuromuscular (EENM), utilizou-se gerador de corrente russa, uma corrente sinusoidal alternada (bifásica) de $2.500 \mathrm{~Hz}$ com freqüência de estímulo de $50 \mathrm{~Hz}$ e com um tempo de cada aglomerado de estímulo elétrico (envelope) de $10 \mathrm{~ms}$ e intervalo entre eles de $10 \mathrm{~ms}$. Foram utilizados como parâmetros: ciclo on (período em que há passagem da corrente elétrica) de seis segundos, sendo o rise (tempo que a corrente necessita para haver total descarga elétrica) de dois segundos e o decay (tempo necessário para cessar o estímulo) de dois segundos; e o ciclo off (período no qual não há passagem de corrente elétrica) de 13 segundos, provocando um total de 10 contrações. A corrente foi transmitida ao animal por meio de cabos e eletrodos (carbonosilicone). Inicialmente foi aplicada uma camada fina de gel hidrofílico de $\mathrm{pH}$ neutro, com aproximadamente $1 \mathrm{~mm}$ de espessura a um eletrodo com formato retangular de dimensões $5 \times 3 \mathrm{~cm}$ fixado na região dorsal inferior do animal. Outro eletrodo utilizado para a estimulação local do músculo gastrocnêmio foi uma caneta desenvolvida em menor escala, com 0,5 cm de diâmetro, acoplada ao ponto motor do músculo gastrocnêmio direito, sendo utilizada uma camada de gel para a adequada condução da corrente ao músculo.

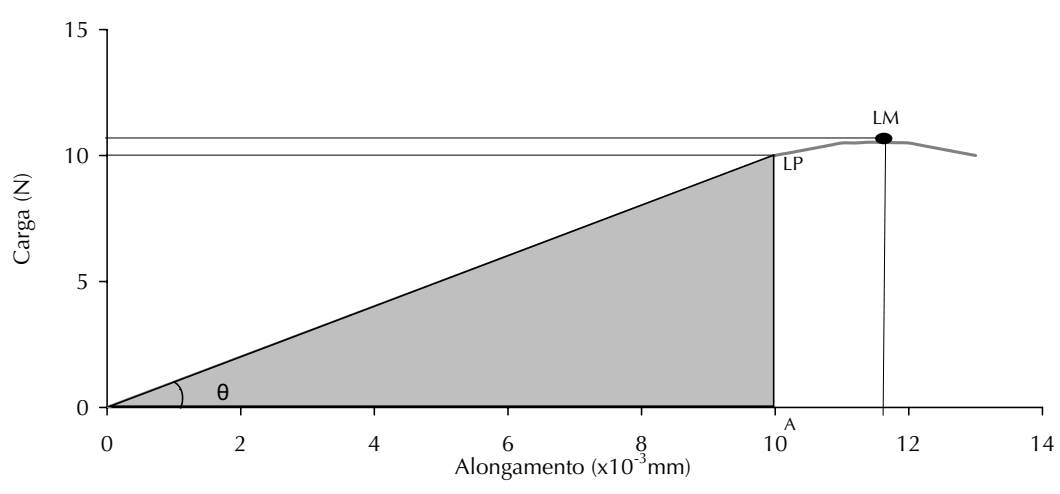

Figura 1 Representação gráfica do ensaio mecânico de tração: ilustração dos pontos utilizados para calcular as propriedades mecânicas do músculo. LM = ponto de interseção das propriedades mecânicas de carga e alongamento no limite máximo; LP = limite de proporcionalidade, representa a transição entre a fase elástica e a fase plástica do músculo; $\theta$ = ângulo formado entre a inclinação da parábola e o eixo x. A rigidez é representada pela tangente do ângulo $\theta$, ou seja, a divisão do segmento LP-A pelo segmento $0-A$; a resiliência é representada pela área do triângulo formado entre os pontos $0-\mathrm{A}-\mathrm{LP}$

\section{Ensaio de tração}

No ensaio mecânico do músculo gastrocnêmio foi utilizada a máquina de ensaio EMIC (modelo DL-3000, do Laboratório de Pesquisa em Materiais Odontológicos da Universidade de Uberaba), equipada com uma célula de carga Kratos de 50 kgf de capacidade. A máquina estava ligada a um microcomputador equipado com o programa Tesc, capaz de captar os valores de carga e alongamento do músculo durante os ensaios mecânicos. Dentre os parâmetros de execução do ensaio, a velocidade de tração longitudinal foi padronizada em $10 \mathrm{~mm} / \mathrm{min}$. O músculo gastrocnêmio foi inicialmente dissecado, sendo os animais sacrificados previamente com superdosagem dos já mencionados anestésicos, preservando sua origem (fêmur) e inserção (calcâneo), o que permitiu, por meio de um acessório metálico, a fixação do complexo osso-tendão-músculo-tendãoosso na máquina de ensaio. Para cada aumento de carga aplicada ao músculo, foi obtido um valor resultante de alongamento, o que possibilitou a construção de gráficos carga versus alongamento, por meio do programa Microsoft Excel 2003.

Feitos os gráficos, puderam ser efetuados os cálculos das propriedades mecânicas carga no limite máximo, alongamento, rigidez e resiliência. A Figura 1 ilustra os pontos e segmentos necessários para os cálculos dessas propriedades. A carga no limite máximo (CLM) corresponde ao ponto gráfico de maior valor de força em Newton (N) obtido pelo músculo no ensaio de tração. A propriedade de alongamento no limite máximo (ALM) é representada pelo maior valor de deformação em milímetros. A rigidez representa o quanto o músculo é capaz de deformar sem que seja danificada a arquitetura muscular. Por fim, a propriedade de resiliência é o quanto de energia o músculo é capaz de absorver na fase elástica.

\section{Análise estatística}

Os dados relativos às quatro propriedades estudadas foram submetidos inicialmente ao teste de normalidade de Kolmogorov Smirnov. Após constatada a normalidade de distribuição, foram utilizados os testes: Anova para análise simultânea dos grupos e Tukey-Kramer para comparação entre os grupos, adotando-se para os testes significância de 5\%.

\section{RESULTADOS}

O valor médio de massa corpórea obtida dos animais ao final do experimento foi de 227,14 $15,0,9$ g; comparando-se com a média inicial de $220,75 \pm 20,11 \mathrm{~g}$, não houve diferença estatística $(p>0,05)$. 

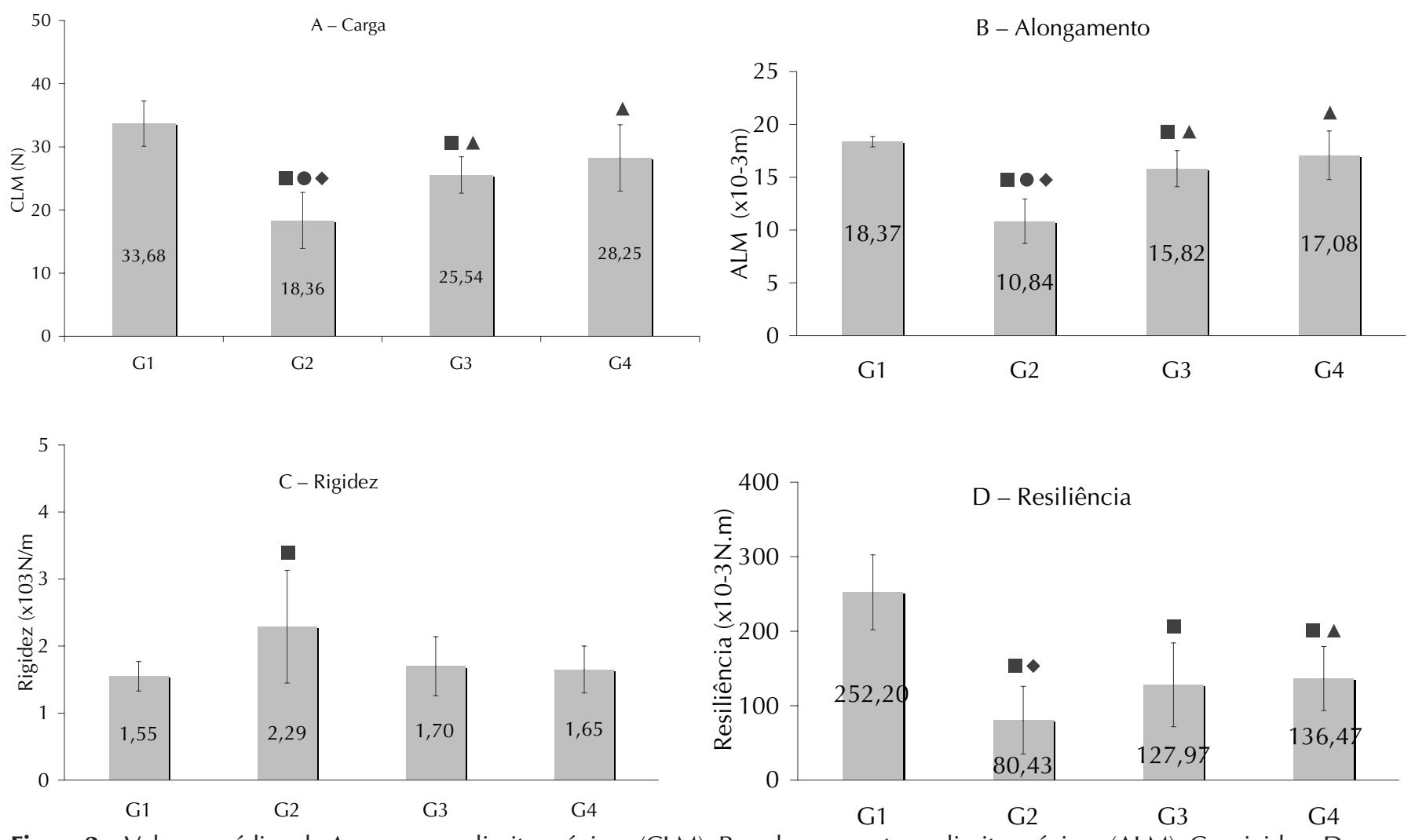

Figura 2 Valores médios de $\mathrm{A}$ = carga no limite máximo $(\mathrm{CLM}) ; \mathrm{B}=$ alongamento no limite máximo $(\mathrm{ALM}) ; \mathrm{C}=$ rigidez; $\mathrm{D}=$ resiliência; encontrados nos grupos controle (G1), imobilizado (G2), imobilizado e liberado (G3) e imobilizado e eletroestimulado (G4). Teste de Tukey-Kramer $(p<0,05)$ : $\_$vs G1; $\mathbf{\Delta}$ vs G2; • vs G3; vs G4

Ao analisar a propriedade mecânica de carga no limite máximo (Figura 2A), observaram-se valores mais altos no G1 comparado aos demais grupos (G2, G3 e G4) $(p<0,05)$. Pela comparação dos grupos G3 e G4 com o G2, evidenciase que tanto a mobilização livre (G2 vs G3, $p<0,05)$ quanto a terapêutica por EENM (G2 vs G4, $p<0,05)$ melhoraram essa propriedade, sendo que a EENM (G4) levou ao maior valor médio, embora sem ter se equiparado ao grupo controle (G1) $(p<0,05)$.

A Figura 2B correspondente à propriedade de alongamento no limite máximo. Pode-se observar que o G2 e o G3 reduziram signifcativamente sua capacidade de alongar, se comparados ao G1 $(p<0,05)$. Semelhante à propriedade de carga no limite máximo, houve difirença significativa $(p<0,05)$ entre os G3 e G4 comparados ao G2, porém quando comparados entre si não foi evidenciada diferença significante $(p>0,05)$. Por outro lado, o G4 apresentou maior valor médio de recuperação que o G3.

A análise dos valores relativos à rigidez dos músculos (Figura 2C) mostra que apenas a comparação G1 vs G2 apresenta $p<0,05$. Assim, pode-se observar aumento não-significativo nos valores médios dessa propriedade nos grupos imobilizado e liberado (G3) e imobilizado seguido por eletroestimulação (G4).

Em relação à resiliência (Figura 2D), foi encontrada diferença significativa $(p<0,05)$ nas comparações G1 vs G2 e G3 vs G4. Vale ressaltar que mesmo o grupo eletroestimulado (G4) tendo apresentado valores inferiores ao grupo controle $(p<0,05)$, estes ainda são superiores aos do grupo apenas imobilizado $(p<0,05)$.

\section{DISCUSSÃO E CONCLUSÃO}

Ao quantificar e analisar a massa corpórea dos animais, verificou-se que o modelo experimental permitiu o livre acesso a água e ração, possibilitando a recuperação e manutenção da massa corpórea, já que os resultados mostram não haver diferença entre as médias das massas antes e após o período experi- mental, confirmando que, mesmo imobilizando o membro posterior do animal, ele é capaz de se alimentar normalmente.

Sabe-se que o tecido muscular se adapta de acordo com o estímulo que Ihe é imposto. Williams e Goldspink ${ }^{19}$ analisaram o músculo sóleo de ratos imobilizados em encurtamento e alongamento nos períodos de um dia a quatro semanas. Observaram que, diferente da posição encurtada, a posição de alongamento não resultou em mudanças no tecido conjuntivo. Os autores concluíram que as alterações musculares decorrentes da imobilização são dependentes da posição da imobilização da articulação, sendo a posição de encurtamento a que provoca maiores prejuízos na função muscular, estando relacionada a maior atrofia das fibras musculares, maior número de pontes cruzadas, redução no número de sarcômeros e conseqüente diminuição do comprimento muscular 6 . No presente estudo, foi possível confirmar essas alterações, sendo observado que os músculos imobilizados reduziram a capacidade de supor- 
tar carga e se alongarem com conseqüente aumento na rigidez e redução na resiliência; após a imobilização, esse músculo estaria assim mais susceptível a lesões tensionais.

Durante a imobilização, as fibras musculares lentas, tipo I, têm maior vulnerabilidade à atrofia se comparadas às fibras musculares rápidas, tipo II. Isso está diretamente relacionado à mudança momentânea do metabolismo, que permanece predominantemente oxidativo durante o período, deixando as fibras susceptíveis à atrofia pela alteração na síntese protéica ${ }^{20,21}$. O músculo gastrocnêmio apresenta metade de suas fibras de contração rápida (fibras tipo II); dessa forma, a composição mista desse músculo o indica para estudar os efeitos da inatividade. Quando o músculo gastrocnêmio é inativo por suspensão do suporte de peso não há geração de atrofia, quando comparado à inatividade por imobilização gessada ${ }^{21,22}$.

Järvinen et al. ${ }^{17}$ encontraram que a imobilização do membro posterior de ratos por períodos maiores que sete dias em posição de encurtamento apresentam redução das propriedades biomecânicas, destacando a redução da elasticidade do músculo, bem como redução da capacidade de absorver energia. No presente estudo, foi visto que a rigidez do grupo submetido apenas à imobilização em posição encurtada apresentou valores superiores quando comparado aos demais grupos, concordando com os estudos de Caierão et al. ${ }^{23}$ e Mcdonough ${ }^{24}$. Esses autores relataram que a imobilização propicia o acúmulo de tecido conjuntivo no tecido muscular, fazendo com que as fibras colágenas tenham contato mais íntimo umas com as outras, podendo estimular a formação de ligação cruzada anormal, o que resulta em perda da extensibilidade e aumento na rigidez tecidual. Dentre os fatores que poderiam interferir, alterando as propriedades mecânicas do músculo, encontrase o aumento da quantidade de tecido conectivo produzido pela matriz extracelular nas fibras musculares. Todavia, a imobilização por um período de 14 dias não seria capaz de proporcionar um aumento de tecido conectivo significativo, capaz de induzir tais alterações mecânicas ${ }^{25}$. As alterações encontradas no presente estudo estariam relaciona- das a outras causas que ainda não foram evidenciadas pela avaliação mecânica, mas que talvez pudessem ser elucidadas com auxílio de uma avaliação histomorfológica.

Tendo em vista as alterações nas estruturas e funções musculares que a imobilização desencadeia, ao se efetuar um tratamento adequado, a plasticidade muscular demonstra a capacidade de retorno de suas propriedades originais ${ }^{26}$.

Este estudo focalizou a eletroestimulação com corrente russa pois, de acordo com a literatura, a eletroestimulação com corrente de média freqüência modulada a $50 \mathrm{~Hz}$ é capaz de restabelecer as propriedades do músculo esquelético ${ }^{26}$.

Após períodos de imobilização, os efeitos deletérios musculares podem ser minimizados e/ou revertidos por meio de recursos como a mobilização e o alongamento. Autores relatam que a mobilização ativa pode auxiliar no desaparecimento do edema, aumento da extensibilidade, organização e regeneração das miofibrilas ${ }^{27}$. A mobilização também é importante para reorganização do tecido conjuntivo ${ }^{23}$. Isso porque o exercício promove alinhamento mais funcional das fibras colágenas, minimizando o surgimento de aderências no tecido cicatricial após lesão muscular ou período de imobilização ${ }^{27}$. Além disso, segundo Stone ${ }^{28}$, o exercício físico pode aumentar a força do tecido conjuntivo, bem como a massa muscular, tornando o músculo mais resistente. Neste estudo, pôde-se confirmar que a movimentação livre é capaz de aumentar os limites de alongamento e rigidez.

Este estudo incluiu um grupo imobilizado e posteriormente liberado (G3). Os resultados corroboram achados histológicos segundo os quais animais imobilizados por 14 dias e em seguida liberados na gaiola por 10 dias apresentam menor perda do diâmetro das fibras tipo I e II em relação ao grupo imobilizado $^{29,30}$. As fibras musculares de contração rápida (tipo II) são recrutadas para acrescentar força muscular e agilidade ao movimento; estas respondem às freqüências na faixa de 50-150 Hz. As fibras do tipo I (contração lenta) são as primeiras a se tornarem ativas; têm uma freqüência tetânica de 20-30 Hz. Assim, para restabelecer a força muscular per- dida durante a imobilização, optou-se por utilizar uma freqüência de $50 \mathrm{~Hz}$ pois, segundo relatos da literatura, após um período de 14 dias de imobilização eletroestimulando o músculo com essa freqüência são restabelecidas algumas propriedades mecânicas como rigidez, resiliência, carga e alongamento no limite máximo ${ }^{17}$.

A estimulação neuromuscular seria capaz de gerar hipertrofia nas fibras tipo II, preferencialmente eletroestimuladas à freqüência de $50 \mathrm{~Hz}$. Neste estudo, pôde-se confirmar que a estimulação por corrente russa a uma freqüência de 50 Hz é capaz de devolver ao músculo pósimobilizado suas propriedades de carga máxima, alongamento máximo e rigidez. O deficit nas propriedades mecânicas pode estar vinculado ao acúmulo de tecido conjuntivo junto ao tecido muscular. Autores relatam que a imobilização de músculo em encurtamento e eletroestimulado levou à redução dos sarcômeros em série, mas não provocou mudanças na constituição de tecido conjuntivo ${ }^{30-31}$. Pode-se pois concluir que a atividade contrátil limita a proliferação de tecido conjuntivo em músculos imobilizados. Esses resultados foram reforçados por pesquisadores que investigaram os efeitos da imobilização com e sem o uso da eletroestimulação no músculo tibial anterior de coelhos e concluíram que a EENM foi eficiente em prevenir a proliferação de tecido conjuntivo no grupo que foi imobilizado e eletroestimulado ${ }^{31-32}$.

Verificou-se aqui que, após a imobilização, a EENM por corrente russa, seguindo o protocolo proposto, foi capaz de restabelecer as propriedades mecânicas de rigidez, carga e alongamento no limite máximo, porém não aumentou os valores de resiliência do músculo até o nível do controle, sugerindo a necessidade de um período superior a 10 dias de estimulação elétrica. Evidencia-se que a reabilitação utilizando a eletroestimulação por corrente russa pode ser um recurso bem empregado visando o reestabelecimento das aptidões físicas relacionadas às disfunções musculares decorrente de contusões, estiramentos, fraturas, pós-operatórios, lesões ligamentares, entre outros motivos que levam à imobilização por aparelho gessado ou por inatividade. 


\section{REFERÊNCIAS}

1 Whiting WC, Zernicke RF. Biomecânica da lesão musculoesquelética. Rio de Janeiro: Guanabara Koogan; 2001.

2 Wang LC, Kernell D. Quantification of fibre type regionalization: an analysis of lower hindlimb muscles in the rat. J Anat London. 2001;198:295-308.

3 Brancaccio N, Klein AA, Böettche GA, Colla PHS, Machado DM, Moser GR, et al. Análise de lesão muscular em ratos treinados e sedentários submetidos à crioterapia. Fisioter Mov. 2005;18(1):59-65.

4 Lehto MUK, Jarvinen MJ. Muscle injuries, their healing process and treatment. Ann Chir Gynaecol. 1991;80(2):102-8.

5 Venojarvi M. Recovery from immobilization: responses of fast-twitch muscle fibres to spontaneous and intensive exercise in rat calf muscles. Pathophysiology. 2004;11:17-22.

6 Booth FW. Time course of muscular atrophy during immobilization of hindlimbs in rats. J Appl Physiol. 1977;43:656-61.

7 Williams PE, Catanese T, Lucey EG, Goldspink G. The importance of stretch and contractile activity in the prevention of connective tissue accumulation in muscle. J Anat London. 1988;158:109-14.

8 Booth FW, Kelso JR. Protection of rat muscle atrophy by cast fixation. J Appl Physiol. 1973;34:404-6.

9 Musacchia XJ, Steffen JM, Fell RD. Disuse atrophy of skeletal muscle animal models. Exerc Sport Sci Rev. 1988;16:61-87.

10 Faulkner JA, Niemeyer JH, Maxwell LC, White TP. Contractile properties of transplanted extensor digitorum longus muscle of the cat. J Appl Physiol. 1980;238:C120-6.

11 Kasper CE, White TP, Maxwell LC. Running during recovery from hindlimb suspension induces muscular injury. J Appl Physiol. 1990;68:533-9.

12 Carvalho LC, Shimano AC, Picado CHF. Estimulação elétrica neuromuscular e o alongamento passivo manual na recuperação das propriedades mecânicas do músculo gastrocnêmio imobilizado. Acta Ortop Bras. 2008;16:161-4.

13 Jarvinen TAH, Kaariainen M, Jarvinen M, Kalimo H. Muscle strain injuries. Curr Op Rheumatol. 2000;12:155-61.

14 Jarvinen M, Lehto MYK. The effect of early mobilization and immobilization on the healing process following muscle injuries. Sports Med. 1993;15:78-89.

15 Azevedo DC, Carvalho SC, Leal EWPS, Damasceno SP, Ferreira ML. Influência da limitação da amplitude de movimento sobre a melhora da flexibilidade do ombro após um treino de seis semanas. Rev Bras Med Esporte. 2008; 14(2):119-21.

16 Fournier M, Roy RR, Perham H, Simard CP, Edgerton VR. Is limb immobilization a model of muscle disuse? Exp Neurol. 1983;80:147-56.
17 Järvinen $M$, Einola SA, Virtanem EO. Effect of the position of immobilization upon the tensile properties of the rat gastrocnemius muscle. Arch Phys Med Rehabil. 1992;73(3):253-7.

18 Appell HJ. Skeletal muscle atrophy during immobilization. Int J Sports Med. 1986;7(1):1-5.

19 Williams PE, Goldspink G. Connective tissue changes in immobilized muscle. J Anat. 1984;138(Pt 2):343-50.

20 Williams JPC, Street M. Sequential faradism in quadriceps rehabilitation. Physiotherapy. 1976;62(8):252-4.

21 Fulbright JS. Electrical stimulation to reduce chronic toeflexor hypertonicity: a case report. Phys Ther. 1984;64(4):523-5.

22 Appell HJ. Muscular atrophy following immobilization. Sports Med. 1990;7:42-58.

23 Caierão QM, Teodori RM, Minamoto VB. The influence of immobilization on the muscle connective tissue: a review. Fisioter Mov. 2007;20(3):87-92.

24 Mcdonough AL. Effects of immobilization and exercise on articular cartilage: a review of the literature. J Orthop Sports Phys Ther. 1981;3(1):2-5.

25 Johnson MA, Polgar J, Weightman D, Appleton D. Data on the distribution of fiber types in thirty six human muscles: an autopsy study. J Neurol Sci. 1973;18:111-29.

26 Herbison GJ, Jaweed MM, Ditunno JF. Muscle fiber atrophy after cast immobilization in the rat. Arch Phys Med Rehabil. 1978;59:301-5.

27 Matheus JPC, Oliveira JGP, Gomide LB, Volpon JB, Shimano AC. Efeitos da estimulação elétrica neuromuscular durante a imobilização nas propriedades mecânicas do músculo esquelético. Rev Bras Med Esporte. 2007;13(1):55-9.

28 Stone $\mathrm{MH}$. Implications for connective tissue and bone alterations resulting from resistance exercise training. Med Sci Sports Exerc. 1988;20(5):162-8.

29 Järvinen M. Immobilization effect on the tensile properties of striated muscle: an experimental study in the rat. Arch Phys Med Rehabil. 1977;58:123-7.

30 Mattiello-Sverzut AC, Carvalho LC, Cornachione A, Nagashima M, Neder L, Shimano AC. Morphological effects of electrical stimulation and intermittent muscle strech after immobilization in soleus muscle. Histol Histopathol. 2006;21:957-64.

31 Kujala UM, Orava S, Järvinen MJ. Hamstring injuries: current trends in treatment and prevention. Sports Med. 1997;23:397-404.

32 Qin L, Appell HJ, Chan KM, Maffulli N. Electrical stimulation prevents immobilization atrophy in skeletal muscle of rabbits. Arch Phys Med Rehabil. 1997;78(5):512-7. 